Volume 117

Issue 1 Dickinson Law Review - Volume 117,

2012-2013

6-1-2012

\title{
Synthetic Biology: Does Re-Writing Nature Require Re-Writing Regulation?
}

Jordan Paradise

Ethan Fitzpatrick

Follow this and additional works at: https://ideas.dickinsonlaw.psu.edu/dlra

\section{Recommended Citation}

Jordan Paradise \& Ethan Fitzpatrick, Synthetic Biology: Does Re-Writing Nature Require Re-Writing Regulation?, 117 Dick. L. REV. 53 (2012).

Available at: https://ideas.dickinsonlaw.psu.edu/dlra/vol117/iss1/3

This Article is brought to you for free and open access by the Law Reviews at Dickinson Law IDEAS. It has been accepted for inclusion in Dickinson Law Review by an authorized editor of Dickinson Law IDEAS. For more information, please contactlja10@psu.edu. 


\title{
Synthetic Biology: Does Re-Writing Nature Require Re-Writing Regulation?
}

\author{
Jordan Paradise, J.D.* \& Ethan Fitzpatrick, Ph.D.**
}

\begin{abstract}
Technological advancements in the life sciences are continually pressing forward despite frequent and vocal resistance. Examples of such advancements include reproductive technologies, genetics, stem cell research, nanotechnology, and now synthetic biology. In May 2010, the J. Craig Venter Institute, a multidisciplinary scientific organization led by one of the first scientists to sequence the human genome, announced in the journal Science the creation of the first synthetic cell-a manmade, single-celled organism with the ability to self-replicate. While hailed as a monumental step forward for science, the response from opponents was swift: stop the science from going forward, keep the products off the market, and protect society from the inherent and unknown risks.

Recognizing that there are measurable and important differences among advancements in the life sciences in terms of the touchstone riskbenefit dichotomy, this article will examine some promising synthetic biology developments in the medical realm in order to assess the application and performance of the Food and Drug Administration (FDA) regulatory framework. It concludes that the FDA is well equipped to assess and implement protections for products that fit into the traditional clinical trial, review and approval, and post-market regime. However, unlike other developments in the life sciences, synthetic biology poses potential environmental problems not previously contemplated by the limited life-cycle inquiry undertaken by the FDA,

* Associate Professor of Law, Seton Hall University School of Law. Please direct all questions and feedback to jordan.paradise@shu.edu. An earlier version of this article was commissioned by the J. Craig Venter Institute's Policy Group and was vetted to Institute members, legal academics, scientists, and agency representatives participating in their individual capacity at a January 2012 workshop held in Rockville, Maryland. The J. Craig Venter Institute will make a condensed version of this article available as findings resulting from the workshop.

** Seton Hall University School of Law J.D. Candidate, 2013.
\end{abstract}


suggesting that it may be necessary to reassess the regulation of medical products using synthetic biology techniques.

\section{Table of Contents}

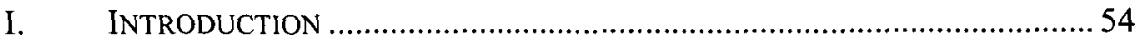

II. THE SCIENCE OF SYNTHETIC BIOLOGY ............................................ 56

III. EXISTING FDA PARADIGMS APPLIED TO SYNTHETIC BIOLOGY .............. 62

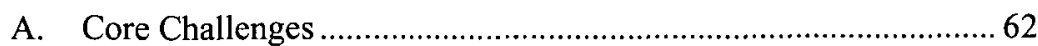

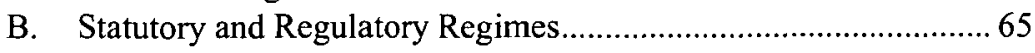

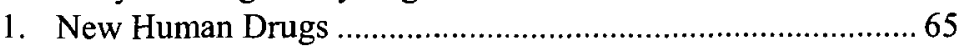

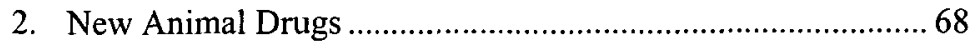

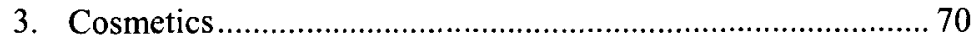

C. A Life-Cycle Approach......................................................... 73

IV. ENHANCING THE REGULATORY LANDSCAPE …................................ 76

A. Human Clinical Trials and Clinical Investigations in Animals..... 76

B. NDA or NADA Review by FDA .............................................. 80

C. Post-Approval and Post-Market.............................................. 82

V. OVERARCHING CONTAINMENT CONSIDERATIONS ............................... 82

A. Reduced-Viability Mechanisms ............................................... 85

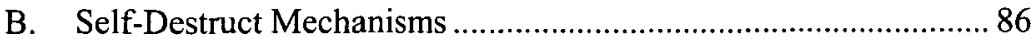

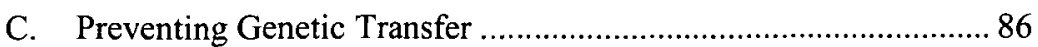

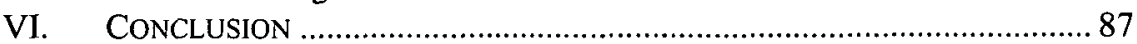

\section{INTRODUCTION}

Technological advancements in the life sciences are continually pressing forward despite frequent and vocal resistance. Examples of such advancements include reproductive technologies, genetics, stem cell research, nanotechnology, and now synthetic biology. The deliberative pattern tends to be similar as the science and the technology unfold: How does it work? How does it differ from previous technologies? What benefits does it add to humanity? What are the impacts on the environment, public health, and society? Is it safe? Are there risks? What are they? Who decides? Are we prepared to regulate it properly?

One unremitting question facing the research and eventual introduction of these advancements in the life sciences is the role of federal regulatory agencies to oversee them. Largely led by consumer interest groups and non-profit organizations, federal regulatory agencies have recently been faced with a barrage of citizens' petitions and litigation claiming, among other things, that their failure to properly regulate the products resulting from these breakthroughs violates their mandate from Congress to protect the public health and welfare. Such 
attacks are commonplace, and recent examples convincingly lay the landscape. In April 2012, the Supreme Court vacated and remanded a high profile Federal Circuit case regarding the U.S. Patent and Trademark Office's stance on the patentability of the genetic sequence that identifies a predisposition to breast and ovarian cancer. 'In addition, a lawsuit filed in December 2011 demands that the Food and Drug Administration (FDA) issue specific regulations in order to oversee sunscreen products containing nanoscale zinc oxide and titanium oxide. ${ }^{2}$ Stem cell research also remains a controversial topic, as the Obama Administration has been challenged for loosening policies over federal funding for embryonic stem cell research from agencies such as the National Institutes of Health. ${ }^{3}$

Enter synthetic biology, a discipline that merges chemistry and biology with engineering in a way that makes many people uncomfortable because it targets the underlying stuff that makes up life itself. Synthetic biology utilizes synthetic biological "parts" to build cells and even entire organisms that can either mimic what occurs in nature or be programmed with wholly novel characteristics. Dr. Drew Endy, a prominent figure in the synthetic biology realm, describes synthetic biology as taking the core materials from just four bottles - the $A, T, G$, and $C$ that constitute the genetic make-up all life forms-and essentially "re-writing" biology. ${ }^{4}$ When the J. Craig Venter Institute (JCVI) announced the creation of the first synthetic cell with the aid of synthetic biology $y^{5}$ a man-made, single-celled organism with the ability to reproduce using a fully synthetic genome--the public reaction was swift. It was simultaneously hailed as both a tremendous discovery with myriad applications that could benefit mankind and a perversion of nature promising to bring the demise of the entire human race. ${ }^{6}$

1. Ass'n of Molecular Pathology v. U. S. Patent \& Trademark Office, 653 Fed. Cir. 1329 (2011), vacated, No. 2010-1406, 2012 WL 1500104, at * 1 (Fed. Cir. Apr. 30, 2012). The case is to be reconsidered in light of Mayo Collaborative Servs. v. Prometheus Labs, Inc., 132 S. Ct. 1289 (2012). That case invalidated patent claims "set[ting] forth processes embodying researchers' findings that identify correlations between metabolite levels and likely harm or ineffectiveness" in the use of thiopurine drugs in the treatment of autoimmune disease as nonpatentable subject matter under the "laws of nature" doctrine. Mayo, 132 S. Ct. at 1290-91.

2. Int'l Ctr. For Tech. Assessment v. Hamburg, Justia.COM, http://dockets. justia.com/docket/california/candce/3:201 lcv06592/249441/ (last visited June 13, 2012).

3. See, e.g., Sherley v. Sebelius, 776 F. Supp. 2d 1, 7-8 (D.D.C. 2011).

4. Drew Endy, Foundations for Engineering Biology, 438 NATURE 449, 449 (2005). A, C, T, and G refer to the four essential nucleotide base pairs that make up DNA: adenine, cytosine, thymine, and guanine. See infra Part II.

5. Daniel G. Gibson et al., Creation of a Bacterial Cell Controlled by a Chemically Synthesized Genome, 329 Scl. 52, 52, 55 (2010).

6. See, e.g., Fiona Macrae, Scientist Accused of Playing God After Creating Artificial Life by Making Designer Microbe from Scratch-But Could it Wipe Out 
Recognizing that there are measurable and important differences among advancements in the life sciences in terms of the touchstone riskbenefit analysis, this article will examine a promising area of synthetic biology research and development to assess the application and performance of the FDA regulatory framework. Microbes modified using synthetic biology techniques have been identified in medical and scientific literature as particularly useful for rapid development and availability of innovative drugs for human and animal use. Proceeding in four parts, this article will examine three product areas: human drugs, animal drugs, and cosmetics. ${ }^{7}$ Part II will provide a general overview of FDA oversight, introduce synthetic biology as applied to medicine, and draw connections among synthetic biology and related technologies. Part III will evaluate the existing FDA statutory and regulatory paradigms applicable to synthetic biology, focusing on the three product areas. Part IV will identify gaps in these paradigms, as applied to synthetic biology, and conclude that, while the FDA's authority under the existing statutory framework is adequate to ensure safety of synthetic biology drug products entering the market, regulatory mechanisms should be bolstered to account for the characteristics of these products and to address novel environmental considerations. To address these conclusions, Part IV will also suggest mechanisms to improve existing legal and regulatory frameworks to encompass synthetic biology utilizing a product life-cycle approach, linking suggestions to periods of premarket (including synthesis and clinical investigations), product application submission and review, and post-approval and post-market. Part $\mathrm{V}$ will discuss overarching containment issues that arise with synthetic biology, urging that the FDA must grapple with novel problems of containment and adjust environmental assessments accordingly. Part $\mathrm{V}$ will also describe and analyze three possible mechanisms to introduce safeguards into the product development process.

\section{THE SCIENCE OF SYNTHETIC BIOLOGY}

Synthetic biology is modeled after genetics. It is the application of principles of nature in a setting that uses synthetically derived materials.

Humanity?, U.K. DAILY MAIL, June 3, 2010, http:/www.dailymail.co.uk/sciencetech/ article-1279988/Artificial-life-created-Craig-Venter--wipe-humanity.html.

7. This article assumes that the definition of "biological product," as currently provided in 42 U.S.C. $\S 262$ (i), is inapplicable to microbes modified using synthetic biology. A biological product is defined as a "virus, therapeutic serum, toxin, antitoxin, vaccine, blood, blood component or derivative, allergenic product, protein (except any chemically synthesized polypeptide), or analogous product, or arsphenamine or derivative of arsphenamine (or any other trivalent organic arsenic compound), applicable to the prevention, treatment, or cure of a disease or condition of human beings." 42 U.S.C. $§ 262(i)(1)$ (2006 \& Supp. 2011). 
In other words, synthetic biology is "the design and construction of new biological parts, devices, and systems that do not exist in the natural world and also the redesign of existing biological systems to perform specific tasks." an understanding of basic genetics and the development and evolution of recombinant deoxyribonucleic acid (rDNA) technology in particular. Two nucleic acids direct heredity and the evolutionary process: deoxyribonucleic acid (DNA) and ribonucleic acid (RNA). ${ }^{9}$ Sequences of RNA and DNA are essentially the genetic code for all life. They are composed of a 5-carbon sugar (either ribose in RNA or 2-deoxyribose in DNA), a phosphate, and a nucleobase. ${ }^{10}$ The nucleobases are adenine $(A)$, guanine $(G)$, cytosine $(C)$, thymine (T), and uracil (U). " RNA and DNA share the bases $A, G$, and $C$, and RNA contains $U$ while DNA contains $T^{12}$ In forming the DNA nucleotide, A pairs with $T, G$ pairs with $\mathrm{C}$, and the phosphate and sugar form the backbone of the double helix. $^{13}$ In a biological process called transcription, the genetic code of DNA is read by separating chains of DNA into single strands that are then used as a template to make a chain of complementary RNA. The RNA is then translated into linear polypeptide chains of amino acids called proteins, which perform the majority of work within the cell. ${ }^{14}$

This process occurs naturally within every cell of the body. The development of rDNA technology introduces foreign genetic material into the natural process. The discovery of rDNA technology is largely attributed to the research of Stanley Cohen and Herbert Boyer. ${ }^{15}$ In the early 1970s, Cohen and Boyer discovered that a protein called a restriction enzyme (also termed a restriction endonuclease) could be used to cleave a portion of DNA called a plasmid that resides in a bacterial cell separate from the chromosome. ${ }^{16}$ This process, often termed

8. ETC GROUP, EXTREME GENETIC ENGINEERING: AN INTRODUCTION TO SYNTHETIC BIOLOGY 1 (2007).

9. James D. WATSON ET AL., RECOMBINANT DNA: GeNeS AND GenOMES-A SHORT COURSE 3 (3d ed. 2007). Strands of DNA and RNA are actually polynucleotides, consisting of numerous nucleotides held together by covalent and hydrogen bonds. Id. at 19.

10. Id. at 13 .

11. Id. at 12 .

12. Id. at 19 .

13. Id. at 18-19. RNA, on the other hand, is single stranded, with A pairing with $\mathrm{U}$ rather than T. Id. at 36 .

14. There are 20 amino acids. WATSON ET AL., supra note 9, at 31. The "RNA molecules ... serve as templates for ordering the amino acids in the polypeptide chains of proteins during the process of translation." Id. at 36 .

15. Stanley N. Cohen et al., Construction of Biologically Functional Bacterial Plasmids In Vitro, 70 PROC. NAT'L ACAD. SCIS. 3240, 3240 (1973). Id.

16. There are both naturally occurring and artificially created restriction enzymes. 
restriction endonuclease digestion, essentially cuts the sugar and phosphate backbone of each side of the double-stranded DNA at a recognized site based on the specific nucleotide sequence. After cutting both strands of the DNA at a specific site, Cohen and Boyen attached foreign DNA material to the cleaved portions of the DNA, creating a novel sequence of DNA consisting of part original DNA and part new DNA. ${ }^{17}$ The DNA double helix was effectively cut and "recombined" to create a novel DNA molecule. Cohen and Boyen then introduced the modified DNA back into the bacterial cell where it would subsequently create identical replications of itself each time the cell divided. ${ }^{18}$

Synthetic biology allows genetic engineering on a level not previously possible; it is the production of biological life, or essential components of living systems, by synthesis. John Glass, the second author of the Science publication describing JCVI's creation of the first synthetic life form, has referred to synthetic biology as a new way of thinking about doing biology and making things: "[I]t is recombinant DNA [technology] on a grand scale." 19 Although rDNA technology requires the procurement of DNA by traditional techniques, such as restriction endonuclease digestion and the use of polymerase chain reaction (PCR) amplification to generate and manipulate nucleotide sequences, ${ }^{20}$ synthetic biology does not. These traditional methods are useful for modifying nucleotide sequences of modest length, but they become impractical or even impossible to use with longer lengths of DNA. The emerging technology of synthetic biology promises to eliminate these existing restrictions through novel methods for chemically synthesizing sequences of DNA, nucleotide by nucleotide. Synthetic biology techniques for DNA synthesis are easier, faster, and cheaper. They can be done without human intervention, i.e., with the aid of robotics, and the resulting unit is an entire genome rather than individual dissociated groups of genes. ${ }^{21}$ Dr. J. Craig Venter describes

17. Id.

18. Id. at 3244 .

19. Dr. John Glass, Senior Scientist, JCVI Synthetic Biology Grp., Presentation at the J. Craig Venter Inst:: Assessing the Federal Regulatory Framework for Synthetic Biology Products (Jan. 30, 2012) [hereinafter JCVI Presentation].

20. Polymerase chain reaction is a molecular biology technique used to generate copies of DNA. Randall K. Saiki et al., Enzymatic Amplification of Beta-Globin Genomic Sequences and Restriction Site Analysis for Diagnosis of Sickle Cell Anemia, 230 SCI. 1350 (1985), available at http://www.sciencemag.org/site/feature/data/ genomes/230-4732-1350.pdf.

21. JCVI Presentation, supra note 19. During the JCVI presentation, Dr. Glass noted that anything he could type into a computer using $A, T, C$, and $G$ he could synthesize whether or not it has a biological utility. However, he emphasized that JCVI's policy is not to make anything that has not already existed in nature. Id. 
the new techniques as enabling scientists to "re-engineer the genome in a much more logical fashion.",22

Equally important as the chemical synthesis of DNA is the ability to engineer the synthesized DNA sequences to do something useful. For synthetic biology to reach its full potential, it is not enough to be able to synthesize whole genomes; it will also be necessary to program those genomes to perform some desired molecular function. Using single genes as modular units, synthetic biologists are in the process of creating component libraries with standardized functions that can be used for bottom-up design of novel synthetic gene networks or even novel whole genomes. $^{23}$ Using these modular gene components, and with inspiration coming from electrical circuits, synthetic gene circuits are becoming increasingly sophisticated. Currently, scientists have engineered gene networks to work as "timers, counters, clocks, logic processors, pattern detectors, and intercellular communication modules."24

Although in its infancy, the advanced synthesis and engineering techniques of synthetic biology have the potential to significantly impact the field of medicine. Attempts are currently underway to rationally design human and animal therapies in an engineering-like fashion. ${ }^{25}$ This synthetic biology approach to medicine involves contemplating living things as being composed of vast biological circuits that can be rewired to interrupt a diseased state. ${ }^{26}$ One goal of synthetic biology, as applied to medicine, is to design synthetic gene circuits that can be integrated into a native malfunctioning gene circuit in order to restore the native normal state. ${ }^{27}$ In the case of infectious diseases, a synthetic gene network would be engineered to interrupt the normal gene networks of the pathogen. ${ }^{28}$ Design of novel biomolecules, gene networks, and programmable organisms are but a few examples of ways in which synthetic biology is currently being used to strike the molecular mechanisms underlying disease. ${ }^{29}$ In several areas, synthetic biology is projected to play a critical role in solving problems where traditional biomedical therapies have failed. At present, researchers are attempting

22. Wil S. Hylton, Craig Venter's Bugs Might Save the World, N.Y. TIMES, May 30, 2012, http://www.nytimes.com/2012/06/03/magazine/craig-venters-bugs-might-save-theworld.html?pagewanted=1\&r=1\&emc=eta1\#.

23. See David Sprinzak \& Michael B. Elowitz, Reconstruction of Genetic Circuits, 438 NATURE 443 (2005); Endy, supra note 4.

24. Warren C. Ruder et al., Synthetic Biology Moving into the Clinic, $333 \mathrm{SCI} .1248$ (2011).

25. Id. at $1248-49$.

26. Id. at 1249 .

27. $I d$.

28. Id. at 1250 .

29. See Ruder et al., supra note 24 , at 1249. 
to develop vaccines, design treatments for bacterial infection and cancer, and facilitate regenerative cell therapy using the engineering principles of synthetic biology. ${ }^{30}$ Synthetic biology is enabling microbiome engineering employed for therapy, i.e., modifying the microorganisms that are naturally associated with the human body to prevent disease. The technology of synthetic biology is continually evolving and will undeniably reach a level of sophistication that allows clinical application of synthetic biology in humans and animals. The eventual promise in clinical applications requires a parallel focus on the resulting implications of widespread development and use.

Synthetic biology builds on core scientific techniques that support current medical technologies. However, there are two major differences between medical therapies employing synthetic biology and medical therapies employing traditional rDNA techniques. The first difference lies in the sheer scale of genetic modification. Compared to rDNA techniques, synthetic biology methods allow for greater and more novel genetic variation from what exists in nature. Medical therapies developed using rDNA techniques have traditionally involved modification of a single gene. ${ }^{31}$ The quintessential example of a successful rDNA technology is the development of recombinant human insulin, which has almost entirely replaced insulin derived from animal sources. $^{32}$ Cohen and Boyer's groundbreaking work with E.coli in the 1970 s ushered in these advancements in insulin production. The recombinant insulin is produced by expressing the human insulin gene in an E.coli bacterium. The recombinant human insulin is expressed in the bacterium and then harvested, purified, and used to treat patients with diabetes. $^{33}$ This type of genetic engineering is not very sophisticated compared to synthetic biology; the human insulin gene is simply engineered to be expressed, independent of any other gene. In contrast, a synthetic biology approach to developing a medical therapy would involve engineering multiple genes that work in concert to form a gene circuit. $^{34}$ This gene circuit would involve synthetic genes "uploaded" into the synthetic cell as well as native genes of the treated organism. ${ }^{35}$ This type of genetic engineering is far more complex and requires

30. Id.

31. Subin Mary Zachariah \& Leena K. Pappachen, A Study Of Genetic Engineering Techniques In Biotechnology Based Pharmaceuticals, 3 INTERNET J. NANOTECH. 1 (2009).

32. The M.J., Human Insulin: DNA Technology's First Drug, 46 AM. J. HEALTHSys. PharmaCy S9 (1989).

33. Cohen et al., supra note 15.

34. See Ruder et al., supra note 24.

35. Id. at 1249 . 
significantly more genetic modification than the simple rDNA expression of a protein.

The second core difference between medical therapies employing synthetic biology and medical therapies employing rDNA techniques lies in the resulting product used as a treatment. Therapies based on rDNA technology are created using a genetically altered organism, but the product ultimately used as the drug is far removed from that organism. Recombinant human insulin is also a useful illustration of the typical rDNA product, where the genetically modified E.coli are used to express the recombinant insulin but are not used in the actual therapy. In contrast, a microbe engineered using synthetic biology techniques would be used as the "drug" itself." The living synthetic organism would be engineered to live, at least temporarily, inside a patient's body in order to employ the engineered gene network and treat the disease. ${ }^{37}$ This difference makes the engineering of complicated biological networks possible and allows for the use of whole organisms as drugs. Unfortunately, this difference may also create more uncertainty in the event of exposure to or release into the natural environment.

The use of an engineered living organism as a drug also leads to novel problems such as: (1) the detection or prevention of escape from the host; (2) the potential infection of humans or animals; and (3) the impact on natural ecosystems due to the fact that engineered synthetic organisms have been designed to live inside a human or animal and thus have the potential to multiply and evolve over time. Traditional approaches to developing medicine, however, do not involve the use of a living organism with potential to evolve as a therapy, and therefore do not raise similar concerns. For example, a traditional small molecule drug is by design partly or wholly metabolized by a patient's body and excreted into the environment. Any human or animal exposed to that drug or metabolite would not likely be affected by it because the concentration of the drug would be very low once it is diluted in the environment. In contrast, when a living organism is used as the drug itself, dilution into the environment is irrelevant because it continues to function as an organism rather than being metabolized by the body. A single engineered cell released into the environment could make its way into a third-party human or animal and multiply to a significant population. Theoretically, unintended contact with even a single synthetic microbe could result in that third party receiving a therapeutic dose of the synthetic biology drug.

36. Id. at 1251 .

37. Id. 
Notably, these concerns of scale and end product do not apply to products that use current rDNA techniques in the food context. One of these products is the genetically engineered Aquadvantage salmon intended for human food, a developing product that has received recent attention from the press and the FDA. ${ }^{38}$ There, the resulting organism, the genetically engineered salmon, is macroscopic; the animal drug introduced into the salmon does not self-replicate, and the drug is not transmittable to anything other than the salmon's offspring.

\section{EXISTING FDA PARADIGMS APPLIED TO SYNTHETIC BIOLOGY}

Given the characteristics and momentum of synthetic biology research and development for medical applications, it is important to identify areas in which the current FDA framework may be deficient and to suggest possible approaches for the FDA in regulating synthetic biology. This Part details the existing FDA statutory and regulatory paradigms for new drugs, animal drugs, and cosmetics. ${ }^{39}$ It will introduce basic statutory and regulatory concepts and will identify areas where existing paradigms may be inadequate for synthetic biology products.

\section{A. Core Challenges}

The FDA faces several general challenges in the regulation of any marketed product within its purview given the authority granted to it by Congress. The first challenge concerns the vast amount of products that the FDA is responsible for overseeing and the legal framework dealt to it by statute. The FDA oversees approximately 25 percent of consumer products on the market in the United States. ${ }^{40}$ The legal and regulatory framework varies according to the type of product, but an underlying

38. See, e.g., Shannon Cameron, FDA Holds Public Meeting on GE Salmon, FDA VETERINARIAN NEWSLETTER, Dec. 16, 2010, available at http://www.fda.gov/Animal Veterinary/NewsEvents/FDAVeterinarianNewsletter/ucm235437.htm; FDA, CTR. FOR VETERINARY MED., BRIEFING PACKET: AQUADVANTAGE SALMON (2010) [hereinafter FDA BRIEFING PACKET], available at http://www.fda.gov/downloads/AdvisoryCommittees/ CommitteesMeetingMaterials/VeterinaryMedicineAdvisoryCommittee/UCM224762.pdf ?utmcampaign $=$ Google $2 \& u$ tmsource $=$ fdaSearch $\& u t m m e d i u m=$ website \&utmterm $=$ aquad vantage\&utmcontent $=3$.

39. The new human drugs section is adapted from Jordan Paradise, Reassessing Safety for Nanotechnology Combination Products: What Do Biosimilars Add to Regulatory Challenges for the FDA?, 56 ST. LouIS U. L.J. 465 (2012). Many future synthetic biology products may also integrate features of drugs, biologics, and devices that may trigger the combination products approach. See Combination Products, FDA, http://www.fda.gov/combinationproducts/default.htm (last visited Aug. 8, 2012).

40. FDA, AdVANCING RegUlatory SCIENCE at FDA: A STRATEgic Plan (2011), available at http://www.fda.gov/ScienceResearch/SpecialTopics/RegulatoryScience/ ucm267719.htm\#browse. 
construct is that each area of oversight is characterized by a statutorily defined product rather than a defined process. This definitional aspect is challenging for both the FDA and the regulated industry. The FDA has been repeatedly confronted with new technologies and products that straddle the definitional boundaries provided in the Food, Drug, and Cosmetic Act (FDCA). ${ }^{41}$ Commentators argue that the definitional focus of the statutory scheme has caused a "silo effect," forcing rigid compartmentalization where it is often inappropriate. ${ }^{42}$ Our depiction of the silo effect in Figure 1 uses buckets to represent the compartmentalization in the context of new drugs, animal drugs, and cosmetics. As with any emerging technology that integrates scientific and technological aspects, these definitional aspects will prove particularly challenging for synthetic biology.

\section{Figure 1. FDCA Definitional Product Buckets}

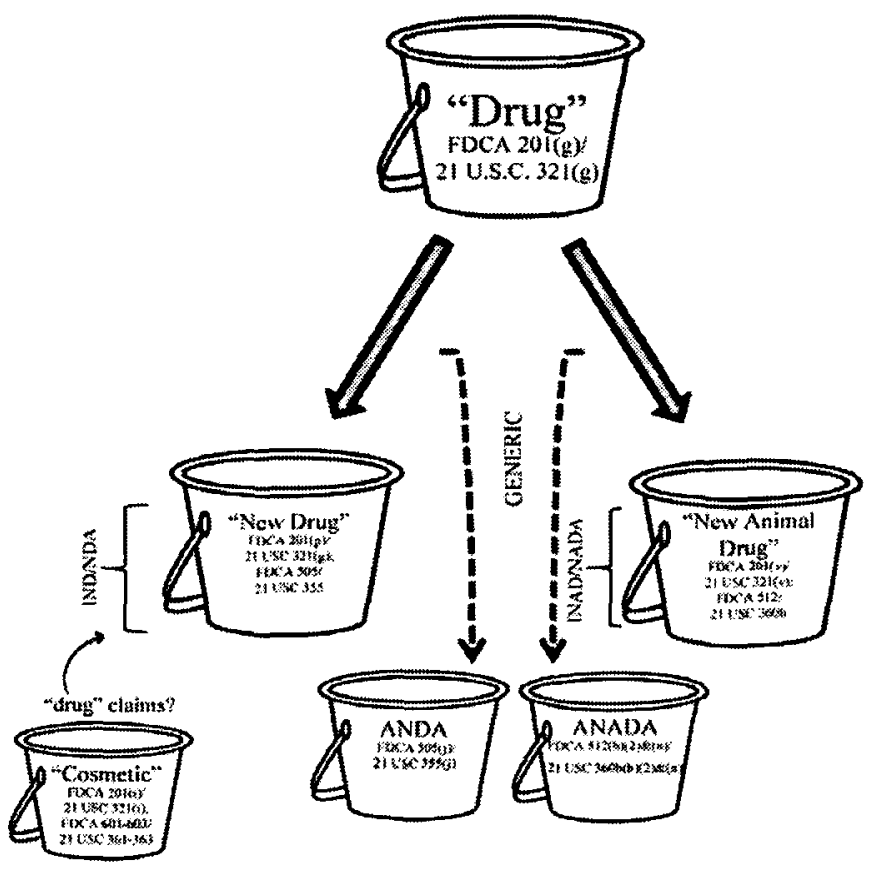

41. This was the opinion of the FDA with regard to recombinant DNA technology used in food products (addressing the question of whether the rDNA was generally recognized as safe under the food regime). See infra Part III.B.

42. Susan B. Foote \& Robert J. Berlin, Can Regulation Be as Innovative as Science and Technology? The FDA's Regulation of Combination Products, 6 MINN. J. L. SCI. \& TECH. 619, 623 (2005). 
As Figure 1 indicates, "drug" is an umbrella term defined in the FDCA. $^{43}$ The primary feature of this definition is that the intended use of the product is either to diagnose, cure, mitigate, treat, or prevent disease in man or animal; or to affect the structure or function of the body of man or animal. ${ }^{44}$ A "drug" is then subdivided into two categories within the FDCA: a "new drug"45 and a "new animal drug,",46 which both require a showing of safety and efficacy for product approval. $^{47}$ Each of those categories also provides for an abbreviated route to market, often termed a "generic drug" route, requiring a showing of bioequivalence to an existing FDA approved drug rather than requiring full-scale trials for safety and efficacy. ${ }^{48}$ There are also drug compositions that are "generally recognized as safe and effective" (GRAS), termed nonprescription or "over-the-counter drugs" (OTC). ${ }^{49}$ These compositions generally fall outside the scope of a "new drug" and can enter the market if they adhere to OTC Monographs and accompanying limitations established by the FDA. ${ }^{50}$ This article will focus on the "new drug" and "new animal drug" buckets, as these are the routes to market that synthetic biology drugs will travel when they begin to enter the marketplace.

Similar to the drug buckets created in the FDCA, cosmetics are defined by their intended use-to cleanse, beautify, promote attractiveness, or alter appearance. ${ }^{51}$ As will be discussed in Part III.B, manufacturer labeling and marketing claims can move a cosmetic into the drug bucket where the intended use explicitly or implicitly drifts into the scope of the drug definition. Although this article will not focus on the regulation of cosmetics, it is useful to identify the relationship between the FDCA definitions and the implications for the industry.

43. See 21 U.S.C. $\S 321(\mathrm{~g})(1)$ (2006 \& Supp. 2011). The term "drug" is further explained infra Part III.B.

44. Id.

45. 21 U.S.C. $\S 321$ (p) (2006 \& Supp. 2011).

46. 21 U.S.C. $\S 321(\mathrm{v})(2006 \&$ Supp. 2011$)$.

47. See 21 U.S.C. $\S 355$ (2006 \& Supp. 2011); 21 U.S.C. $\S 360 \mathrm{~b}(3)(\mathrm{b})(2006$ \& Supp. 2011).

48. See 21 U.S.C. § 355(j) (2006 \& Supp. 2011); 21 U.S.C. $\S \S 360 b(b)(2),(n)(2006$ \& Supp. 2011).

49. This category derives from both the language of the statute (where a new drug is one which "is not generally recognized, among experts qualified by scientific training and experience to evaluate the safety and effectiveness of drugs, as safe and effective for use under the conditions ...") and from the OTC Drug Review, a program initiated by FDA in the 1970 s to designate GRAS drugs. See PeTER B. HutT ET AL., Food and DRUG LAW 788-801 (3d ed. 2006).

50. There are, however, exceptions to this general rule where FDA deems OTC status appropriate for a particular new drug.

51. 21 U.S.C. $\$ 321$ (i) (2006 \& Supp. 2011). 
The FDA's second general challenge is the spectrum of regulatory authority granted to it by statute, with oversight for the most highly regulated product areas covering clinical trials, pre-market review, and post-market timeframes. An ongoing struggle is how to integrate new or changing information and knowledge about risks and benefits as framed by measurements of safety and efficacy. Despite the expanse of FDA authority over the most highly regulated product areas, there are also significant gaps in containment oversight, including the environmental and public health implications of product manufacturing and disposal. This article will address the challenge by utilizing a modification of the "total product life cycle" approach adopted by the FDA's Center for Devices and Radiological Health to visualize the synthetic biology development cycle. ${ }^{52}$ It will identify existing statutory and regulatory provisions at key stages in the cycle. ${ }^{53}$ This approach will frame the remainder of this article.

\section{B. Statutory and Regulatory Regimes}

The product areas of new human drugs and new animal drugs both flow from the general definition of "drug" as provided in the FDCA. ${ }^{54}$ They share core requirements for approval, yet important differences exist in their oversight based on the statute and regulations.

\section{New Human Drugs}

Oversight of both human drugs and animal drugs is set forth in Chapter V of the FDCA..$^{55} \mathrm{~A}$ "drug" is defined as:

(a) articles recognized in the official U.S. Pharmacopeia,...; and (b) articles intended for use in the diagnosis, cure, mitigation, treatment, or prevention of disease in man or other animals; and (c) articles (other than food) intended to affect the structure or any function of the body of man or other animals; and (d) articles intended for use as a component of any articles specified in (A), (B), or $(C){ }^{56}$

This definition references use in both humans and animals. In contrast, a "new drug" is specific to humans and is defined as:

52. Ctr. For Devices and Radiological Health, FDA, CDRH InNovation INITIATIVE 5 (2011), available at http://www.fda.gov/downloads/AboutFDA/Centers Offices/CDRH/CDRHInnovation/UCM242528.pdf.

53. See infra Figure 2.

54. 21 U.S.C. $\$ 321(\mathrm{~g})(1)(2006 \&$ Supp. 2011).

55. 21 U.S.C. $\$ \S 351$ to $360 \mathrm{ccc}-2$ (2006 \& Supp. 2011).

56. 21 U.S.C. $\$ 321(\mathrm{~g})(1)(2006 \&$ Supp. 2011). 
(1) [a]ny drug (except a new animal drug or an animal feed bearing or containing a new animal drug) the composition of which is such that the drug is not generally recognized, among experts qualified by scientific training and experience to evaluate the safety and effectiveness of drugs, as safe and effective for use under the conditions prescribed, recommended, or suggested in the labeling. ... ${ }^{57}$

The New Drug Application (NDA) process for human drugs involves the most rigorous review of any FDA-regulated product and is overseen by the Center for Drug Evaluation and Research (CDER). ${ }^{58}$ It can take upwards of 15 years and cost over a billion dollars to bring a new drug to market. ${ }^{59}$ The touchstone measures of this process are safety and efficacy, but oversight by the FDA spans identification, synthesis, and purification of an active pharmacological ingredient; pre-clinical and animal testing; clinical trials; manufacturing processes; review of the product for final approval; and post-market performance. ${ }^{60}$ New human drugs must satisfy safety, efficacy, and manufacturing standards, among other substantive requirements. ${ }^{61}$ Applicants must progress through key stages in the approval process including an Investigational New Drug application (IND) based on animal studies and three core stages of clinical trials, culminating in an NDA. ${ }^{62}$

Although outside the scope of this article, the FDCA generic drug approval process provides an Abbreviated New Drug Application (ANDA) process, also termed generic approval. ${ }^{63}$ The ANDA process combines patent term extension and data exclusivity provisions with authorization for FDA to approve generic versions of already approved pioneer drugs. ${ }^{64}$ An ANDA does not generally require preclinical and clinical data to establish safety and efficacy but must demonstrate that the product is "bioequivalent" and performs in the same manner as the

57. 21 U.S.C. $\S 321(\mathrm{p})(1)$ (2006 \& Supp. 2011).

58. About the Center for Drug Evaluation and Research, FDA, http://www.fda.gov/ AboutFDA/CentersOffices/OfficeofMedicalProductsandTobacco/CDER/default.htm (last visited Aug. 8, 2012).

59. Chris L. Walle et al., Strategies to Support Drug Discovery through Integration of Systems and Data, 12 Drug DiscoverY TODAY 634 (2007).

60. 21 U.S.C. $\S 355$ (2006 \& Supp. 2011).

61. Id.

62. See Paradise, supra note 39 , at $479-85$ (discussing the NDA process).

63. The Drug Price Competition and Patent Term Restoration Act of 1984 (also known as the Hatch-Waxman Act) established the abbreviated new drug application process currently codified at 21 U.S.C. $\& 355(j)$. See Drug Price Competition and Patent Term Restoration Act of 1984, Pub. L. No. 98-417, 98 Stat. 1585 (codified as amended in scattered sections of $15,21,35$, and 42 U.S.C.).

64. 21 U.S.C. \& 355(j) (2006 \& Supp. 2011). 
pioneer drug in terms of active ingredient, dosage and route of administration, and strength and conditions of use. ${ }^{65}$

For both human and animal drugs, the FDA has the authority to withdraw an approved application after notice and opportunity for a hearing. ${ }^{66}$ Findings that generally support withdrawal in both contexts include: failure to maintain records; violations of good manufacturing practices; violations of labeling requirements and limitations; experience, scientific data, or new evidence showing that the drug is unsafe or that it has not been shown to be safe for use under the conditions of use; new information showing a lack of substantial evidence of efficacy; or a showing of an imminent hazard to health of man or animal (in such case the withdrawal of approval is available immediately). ${ }^{67}$

Increasing concern about the failure to assure that industry fulfills post-approval commitments led to the Food and Drug Administration Amendments Act of 2007 (FDAAA). ${ }^{68}$ Before 2007, the FDA relied on two statutory provisions broadly dealing with maintenance of records and reports as a basis for requests for post-approval nonclinical or clinical studies (aside from those required under the accelerated approval regulations). ${ }^{69}$ The FDAAA now explicitly provides the FDA with the authority to require post-approval studies for human drugs; moreover, the FDA can now rely on new provisions regarding Risk Evaluation and Mitigation Strategies (REMS) and new safety information to require further studies and assessment for safety and efficacy. ${ }^{70}$ REMS come in many forms: they can require a Medication Guide for patients, prescription physician information, implementation plans, communications to health care providers and pharmacies, and various limitations on labeling, promotion, and prescribing to assure safe use. ${ }^{71}$ These amendments provide significant enforcement mechanisms for

65. 21 U.S.C. $\S 355(j)(2)(A)($ ii)-(iii) (2006 \& Supp. 2011). A showing of bioequivalence requires "the absence of a significant difference in the rate and extent to which the active ingredient or active moiety in pharmaceutical equivalents or pharmaceutical alternatives becomes available at the site of drug action when administered at the same molar dose under similar conditions in an appropriately designed study." 21 C.F.R. $\$ 320.1$ (e) (2012).

66. 21 U.S.C. $\S \S 355(\mathrm{e}), 360 \mathrm{~b}(\mathrm{e})$ (2006 \& Supp. 2011).

67. 21 U.S.C. $\S \S 355(\mathrm{e}), 360 \mathrm{~b}(\mathrm{e})(2006 \&$ Supp. 2011).

68. See Pub. L. No. 110-85, 21 Stat. 823 (2007) (codified in scattered sections of 21 U.S.C.).

69. See 21 U.S.C. $\S \S 355(\mathrm{e}),(\mathrm{k})$ (2006 \& Supp. 2011).

70. See 21 U.S.C. $\S \S 355(0)-($ p), $355-1$ (2006 \& Supp. 2011).

71. See Approved Risk Evaluation and Mitigation Strategies (REMS), FDA, http://www.fda.gov/Drugs/DrugSafety/PostmarketDrugSafetyInformationforPatientsand Providers/ucm 1 11350.htm (last visited Aug. 8, 2012) [hereinafter Approved REMS]. 
violations, which are deemed to be misbranding and carry additional civil money penalties for violations. ${ }^{72}$

\section{New Animal Drugs}

The new animal drug provisions are contained in the FDCA, Chapter V, Subchapters A and F. ${ }^{73} \mathrm{~A}$ "new animal drug" is defined as:

any drug intended for use for animals other than man, including any drug intended for use in animal feed but not including such animal feed-(1) the composition of which is such that such drug is not generally recognized, among experts qualified by scientific training and experience to evaluate the safety and effectiveness of animal drugs, as safe and effective for use under the conditions prescribed, recommended, or suggested in the labeling thereof; except that such a drug not so recognized shall not be deemed to be a "new animal drug" if at any time prior to June 25, 1938, it was subject to the Food and Drug Act of June 30, 1906, as amended, and if at such time its labeling contained the same representations concerning the conditions of its use; or (2) the composition of which is such that such drug, as a result of investigations to determine its safety and effectiveness for use under such conditions, has become so recognized but which has not, otherwise than in such investigations, been used to a material extent or for a material time under such conditions. $^{74}$

New animal drugs are also termed veterinary drugs when they are used to diagnose, cure, mitigate, treat, or prevent disease in nonfood-producing animals. $^{75}$

There are many similarities between the NDA process and approval of a new animal drug, with the animal approval process termed the New Animal Drug Application (NADA) ${ }^{76}$ and the generic process termed the Abbreviated New Animal Drug Application (ANADA). ${ }^{77}$ Despite the similarities in approval processes, there are nuances in the measures for safety and efficacy, as well as in the scope and application of supporting regulations. One important difference between the human and animal drug approval process is that new animal drugs are generally exempt

72. 21 U.S.C. $\S \S 352(\mathrm{y})-(\mathrm{z}), 333(\mathrm{f})(4)$ (2006 \& Supp. 2011).

73. 21 U.S.C. $\$ \S 360$ b, 360ccc-(2) (2006 \& Supp. 2011).

74. 21 U.S.C. $\S 321(v)$ (2006 \& Supp. 2011$)$.

75. Where the product is intended to enter the human food supply, both the food and new animal drug requirements apply, and the product is no longer a veterinary drug.

76. 21 U.S.C. $\S 360 b(n)(2006 \&$ Supp. 2011).

77. The ANADA provisions are scattered, with major provisions contained in 21 U.S.C. $\S 360 \mathrm{~b}(\mathrm{~b})(2)$ (2006 \& Supp. 2011) (filing of an ANADA) and 21 U.S.C. $\S 360 \mathrm{~b}(\mathrm{c})(2)(\mathrm{H})(2006$ \& Supp. 2011) (defining "bioequivalence"). 
from an investigational new animal drug filing prior to initiating clinical investigations in animals. ${ }^{78}$ Another difference is that the post-market authority granted by statute is not as extensive for animal drugs. ${ }^{79}$ For example, the FDAAA amendments apply only to new human drugs, not animal drugs. The FDA monitors products once they enter the marketmainly through manufacturing, labeling, and adverse event requirements to assure ongoing safety and efficacy - and maintains the ability to withdraw products from the market, as discussed in Part IV.

With respect to the ongoing controversy over genetically engineered foods, the FDCA position is that, once an NADA or ANADA is approved and effective, a food bearing or containing that rDNA drug is not considered adulterated if used in accordance with the conditions and indications approved by the FDA. ${ }^{80}$ The FDA guidance document entitled Guidance for Industry 187: Regulation of Genetically Engineered Animals Containing Heritable Recombinant DNA Constructs provides:

An rDNA construct that is in a GE animal and is intended to affect the animal's structure or function meets the definition of an animal drug, whether the animal is intended for food, or used to produce another substance. Developers of these animals must demonstrate that the construct and any new products expressed from the inserted construct are safe for the health of the GE animal and, if they are food animals, for food consumption. ${ }^{81}$

Thus, the FDA will approve two articles when the product is a food that humans will consume: (1) the construct as an animal drug and (2) the food containing that construct as a food safe for human consumption.

Once such a determination is made regarding approval of an rDNA food product, the FDA must amend the animal drug regulations to reflect particular products. ${ }^{82}$ One example that has recently been approved and for which specific regulations have been developed is rDNA products in goat milk:

78. 21 C.F.R. $\S 511.1$ (2012).

79. This distinction is the result of the separate sections of the statute relevant to individual product areas and the scope of Congressional amendments.

80. 21 U.S.C. $\$ 360 \mathrm{~b}(\mathrm{k})$ (2006 \& Supp. 2011).

81. See Genetically Engineered Animals, FDA, http://www.fda.gov/Animal Veterinary/DevelopmentApprovalProcess/GeneticEngineering/GeneticallyEngineered Animals/default.htm (last visited Aug. 9, 2012); see also FDA, GUIDANCE FOR INDUSTRY: REgulation of Genetically ENGINeEREd animals ContanNING Heritable RECOMBINANT DNA CONSTRUCTS (FINAL GUIDANCE) (2011), available at http://www.fda.gov/downloads/AnimalVeterinary/GuidanceComplianceEnforcement/ GuidanceforIndustry/UCM1 13903.pdf.

82. See 21 C.F.R. $\S \S 510,528$ (2012). 
The Food and Drug Administration (FDA) is amending the animal drug regulations to reflect the original approval of a new animal drug application (NADA) filed by GTC Biotherapeutics, Inc. The NADA provides for use of a recombinant deoxyribonucleic acid (rDNA) construct in a lineage of genetically engineered (GE) goats expressing recombinant human antithrombin in their milk. The subsequently purified antithrombin is a biological product for human therapeutic use. In a separate action, a biologics license application (BLA) has been approved by FDA for use of this antithrombin in humans. ${ }^{83}$

To date, the Bc6 rDNA construct regulation is the sole entry in the C.F.R. section relating to new animal drugs in genetically engineered animals.

\section{Cosmetics}

Cosmetics are the least regulated product category that the FDA oversees. In fact, the cosmetic provisions span only three sections in the FDCA, with additional provisions regarding certification for color additives also applicable to certain products. ${ }^{84}$ The term "cosmetic" is defined as:

(1) articles intended to be rubbed, poured, sprinkled, or sprayed on, introduced into, or otherwise applied to the human body or any part thereof for cleansing, beautifying, promoting attractiveness, or altering the appearance, and (2) articles intended for use as a component of any such articles; except that such term shall not include soap. ${ }^{85}$

Although cosmetics are left largely to voluntary self-regulation by the cosmetic industry, the FDA does have an Office of Cosmetics and Colors (OCC) housed in the Center for Food Safety and Applied Nutrition (CFSAN). The OCC is situated within CFSAN due to the regulation of color additives that are often contained in cosmetics. While

83. See Bc6 Recombinant Deoxyribonucleic Acid Construct, 74 Fed. Reg. 6823 (Feb. 11, 2009) (codified at 21 C.F.R. $§ 528.1070$ (2012)). The specification and indications for use in the final regulation reads:

Five copies of a human Bc6 recombinant deoxyribonucleic acid (rDNA) construct located at the GTC 155-92 site in a specific hemizygous diploid line of dairy breeds of domestic goats (Capra aegagrus hircus) directing the expression of the human gene for antithrombin (which is intended for the treatment of humans) in the mammary gland of goats derived from lineage progenitor 155-92.

21 C.F.R. § 528.1070 (2012).

84. See 21 U.S.C. $\$ \S 361-363,379$ e (2006 \& Supp. 2011).

85. 21 U.S.C. $§ 321$ (i) (2006 \& Supp. 2011). 
there is no premarket approval required for cosmetic ingredients, there are premarket approval requirements if the cosmetic product contains a color additive ingredient that has not been listed by the FDA for a specific use in cosmetics. ${ }^{86} \mathrm{~A}$ "color additive" is defined as:

a material which-(A) is a dye, pigment, or other substance made by a process of synthesis or similar artifice, or extracted, isolated, or otherwise derived, with or without intermediate or final chance of identity, from a vegetable, animal, mineral or other source, and (B) when added or applied to a food, drug, or cosmetic, or to the human body or any part thereof, is capable (alone or through reaction with other substance) of imparting color thereto; except that such term does not include any material which the Secretary, by regulation, determines is used (or is intended to be used) solely for a purpose or purposes other than coloring. ${ }^{87}$

Cosmetic regulation also involves the interplay between the FDCA and the Fair Packaging and Labeling Act. ${ }^{88}$ Regulations specific to cosmetics promulgated by the FDA include labeling requirements ${ }^{89}$ and warning statements where there is no adequate substantiation of safety. ${ }^{90}$ All basic cosmetic labels include a statement of identity, net contents, ingredients, and any required warnings. ${ }^{91}$ There are no cosmetic good manufacturing practices as in other FDA regulated areas, although the FDA has provided guidance to the industry. ${ }^{92}$

Nevertheless, a cosmetic product will be subject to the drug approval requirements if it ventures into the realm of a "drug" given the marketing and advertising claims promoted by the manufacturer. Unlike foods, no parenthetical applies to cosmetics in the statutory definition of "drug" providing an exemption for products making structure or function claims; a cosmetic can be classified as a drug if claims are made that the product affects the structure or function of the human body, even if it is a non-therapeutic product. ${ }^{93}$ Heightened claims that a cosmetic will

86. See 21 C.F.R. $\S \S 73-74$ (2012) (discussing color additives exempt from certification).

87. 21 U.S.C. $\$ 321(t)$ (2006 \& Supp. 2011).

88. Fair Packaging and Labeling Act of 1966, Pub. L. 89-755, 80 Stat. 1296 (codified as amended at 15 U.S.C. $\$ \S 1451-61$ (2006)).

89. FDA Cosmetic Labeling, 21 C.F.R. $\$ 701(2012)$.

90. FDA Cosmetic Product Warning Statements, 21 C.F.R. § 740 (2012).

91. Id.

92. See Cosmetic Guidance Documents, FDA, http://www.fda.gov/Cosmetics/ GuidanceComplianceRegulatoryInformation/GuidanceDocuments/default.htm (last visited Aug. 9, 2012).

93. See 21 U.S.C. $\S 321(\mathrm{~g})(1)(\mathrm{C})(2006$ \& Supp. 2011). Foods and dietary supplements can make structure-function claims as long as they do not venture into unallowable health or disease-prevention claims. 
improve health or treat a health or disease-related condition likewise trigger regulation as a drug. Even absent manufacturer claims, a product with a drug or drug-like intended use will be regulated as a drug. The FDA has struggled with the line between a drug and a cosmetic for decades, as reflected in a litany of Warning Letters to industry ${ }^{94}$ and in informational materials located on the FDA's website. ${ }^{95}$ Perhaps stemming from awareness that the line between drug and cosmetic is increasingly blurry, the cosmetic industry has recently pledged support for a federal bill enhancing the FDA's regulatory power over cosmetics. ${ }^{96}$

The regulatory distinction between a drug and a cosmetic is worth examining in the context of synthetic biology products touted as cosmetics, as these products are already in research and development. For example, two European companies have collaborated to manufacture and market cosmetic ingredients using industrial synthetic biology techniques to engineer substitutes for squalane, a skin emollient. ${ }^{97}$ Because of its moisturizing and protective capabilities, coupled with quick penetration into the skin, squalane has widely been used in skin creams and a variety of other cosmetics. ${ }^{98}$ However, squalane is traditionally derived either from olive oil, which suffers from extreme price fluctuation and availability, or from the liver oil of deep sea sharks, which is highly controversial. ${ }^{99}$ The corporate self-proclaimed allure of synthetic squalane is that it will be derived from plant sugars to design yeast, which, in turn, will produce a "renewable" and "sustainable" product. $^{100}$

94. See Warning Letters Address Drug Claims Made for Products Marketed as Cosmetics, FDA, http://www.fda.gov/Cosmetics/GuidanceComplianceRegulatory Information/ComplianceEnforcement/WarningLetters/ucm081086.htm (last visited Aug. 9, 2012).

95. Is it a Cosmetic, a Drug, or Both? (Or Is It Soap?), FDA, http://www.fda.gov/ Cosmetics/GuidanceComplianceRegulatorylnformation/ucm074201.htm (last visited Aug. 9, 2012).

96. See Cosmetic Safety Amendments Act, H.R. 4395, 112th Cong. (2012); Press Release, Pers. Care Prods. Council, Nation's Cosmetic Companies Call for Enhanced FDA Role in Ensuring Safety of Personal Care Products (Apr. 19, 2012), available at http://www.personalcarecouncil.org/newsroom/20120419.

97. See Katie Nichol, Soliance Partners with Amyris to Produce Renewable Squalane, COSMETICSDESIGN-EUROPE.COM (June 23, 2010), http://www.cosmeticsdesigneurope.com/Formulation-Science/Soliance-partners-with-Amyris-to-produce-renewablesqualane; Renewable Cosmetic Ingredients, AMYRIS.COM, http://www.amyris.com/ markets/chemicals/cosmetics (last visited Aug. 9, 2012).

98. See supra note 97.

99. See supra note 97.

100. See supra note 97 . 


\section{A Life-Cycle Approach}

FDA oversight typically begins well after a chemical composition has been synthesized and identified in the laboratory setting. To visualize the chronology and application of existing statutes and regulation, Figure 2 depicts a life-cycle approach to synthetic biology development, beginning with initial laboratory investigations guided mainly by the National Institutes of Health Guidelines for Research Involving Recombinant DNA Molecules ("NIH Guidelines"). ${ }^{101}$ The NIH Guidelines specify construction and handling practices for rDNA molecules and organisms, and for viruses that contain rDNA molecules. ${ }^{102}$ The NIH Guidelines define rDNA molecules as either "molecules that are constructed outside living cells by joining natural or synthetic DNA segments to DNA molecules that can replicate in a living cell" or "molecules that result from the replication of [aforementioned molecules]."

Synthetic DNA segments which are likely to yield a potentially harmful polynucleotide or polypeptide (e.g., a toxin or a pharmacologically active agent) are considered as equivalent to their natural DNA counterpart. If the synthetic DNA segment is not expressed in vivo as a biologically active polynucleotide or polypeptide product, it is exempt from the NIH Guidelines. ${ }^{104}$

The NIH Recombinant Advisory Committee Biosafety Working group has criticized this definition as deficient, as it does not capture synthetic biology using DNA derived exclusively by synthetic methods that is not joined to natural DNA. ${ }^{105}$ To remedy this deficiency, they proposed revisions to the NIH Guidelines that would apply to all synthetic nucleic acids, including those made solely by synthetic means. ${ }^{106}$ The proposed

101. NAT'L INSTS. OF HEALTH, NIH GUIDELINES FOR RESEARCH INVOLVING RECOMBINANT DNA MOLECULES (2011), available at http://oba.od.nih.gov/oba/rac/ Guidelines/NIHGuidelines.pdf.

102. Id. at 10 .

103. Id.

104. Id.

105. The NIH published the proposed modifications to the guidelines for public comment on March 4, 2009. See Recombinant DNA Research: Proposed Actions Under the NIH Guidelines for Research Involving Recombinant DNA Molecules (NIH Guidelines), 74 Fed. Reg. 9411 (Mar. 4, 2009).

106. Id. at 9411 . The proposed language reads:

In the context of the NIH Guidelines, recombinant and synthetic nucleic acids are defined as: (i) Recombinant nucleic acid molecules that are constructed by joining nucleic acid molecules and that can replicate in a living cell, (ii) synthetic nucleic acid molecules that are chemically, or by other means, synthesized or amplified nucleic acid molecules that may wholly or partially 
revisions would also remove the current paragraph regarding the yield of a harmful polynucleotide or polypeptide because the newly crafted definition would sufficiently cover all synthetic nucleic acids. ${ }^{107}$

Figure 2 signals that FDA oversight technically begins at the initiation of clinical investigations in animals or human clinical trials when an FDA approved product is contemplated. However, unless and until the FDA is notified or becomes aware of research involving clinical trials, researchers may illegally circumvent the regulatory process by failing to seek FDA approval before initiating these trials. Additionally, any experimental testing on microbes in an uncontained setting (outside the lab) prior to clinical trials are outside the scope of the NIH Guidelines and the FDA's regulatory reach. ${ }^{108}$ Information and data gathered at earlier experimental stages will feed into and provide support for the eventual IND and NDA or NADA. Figure 2 depicts differences between the new animal drug and new drug clinical trial process with a jagged line: new animal drugs are typically exempt from an Investigational New Animal Drug application (INAD) for purposes of clinical investigations of animals and are subject to submission of an NADA, while new drugs are subject to an IND, human clinical trials, and submission of an NDA. Subject to labeling and other restrictions contained in the regulations, an INAD is not required for in vitro testing, laboratory animal research, or clinical animal investigations of new animal drugs. ${ }^{109}$

contain functional equivalents of nucleotides, or (iii) molecules that result from the replication of those described in (i) or (ii) above.

Id. at 9414-15.

107. Id. at 9415 .

108. Researchers may be required to seek an Environmental Release Application from the Environmental Protection Agency under the Toxic Substances and Control Act (TSCA), 15 U.S.C. $\S \S 2601-92$ (2006); see also 40 C.F.R. § 725 (2012) (discussing EPA reporting requirements for microorganisms).

109. 21 C.F.R. $\S 511.1$ (2012). 


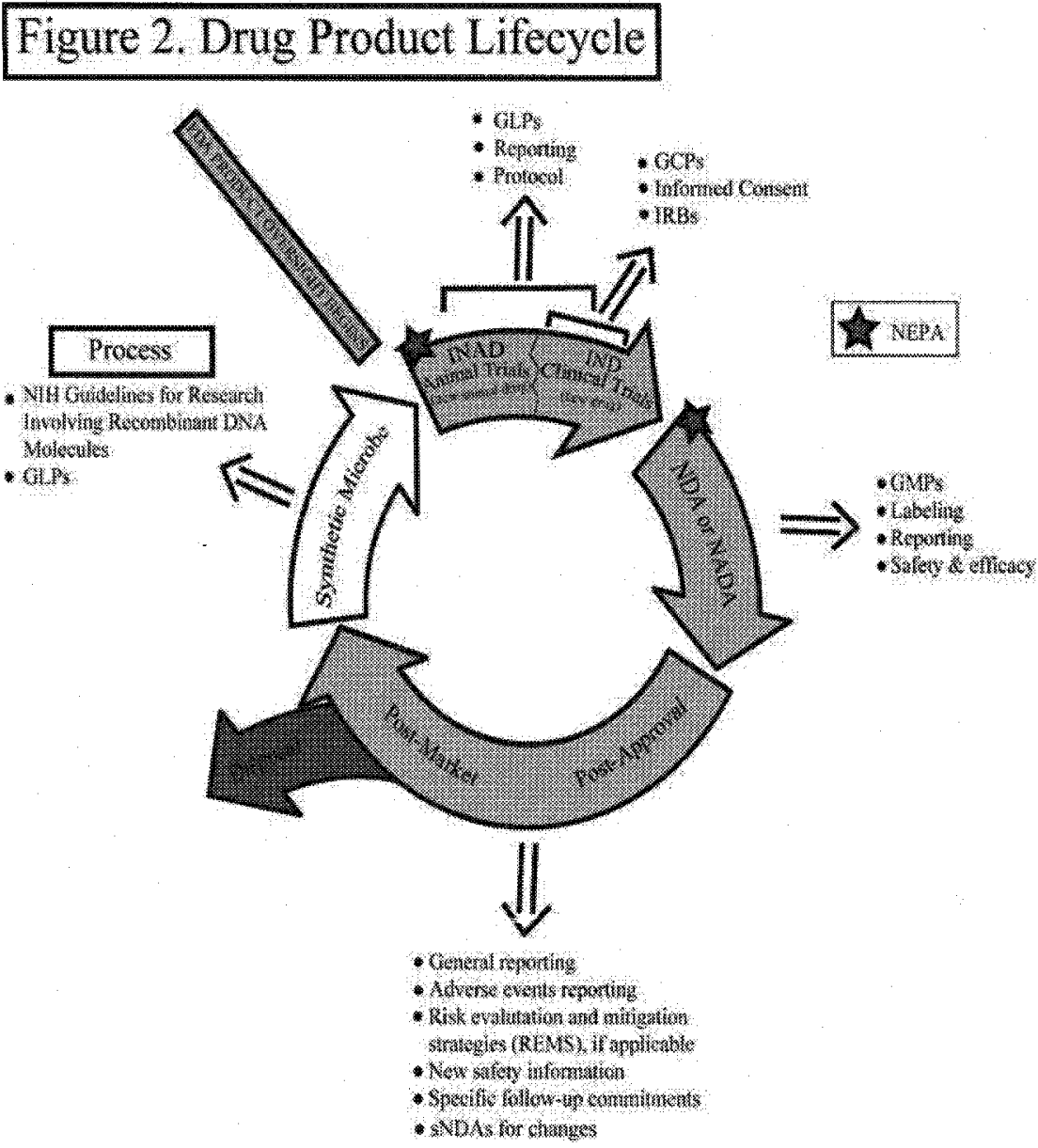

Figure 2 shows that the core phases of the life-cycle of any new drug or animal drug can be categorized as (1) pre-approval (spanning IND human clinical trials and clinical investigations in animals, as applicable); (2) submission of product application and FDA review of the NDA or NADA; and (3) post-approval and post-market. Figure 2 also signals where National Environmental Policy Act (NEPA) ${ }^{110}$ considerations arise throughout these three core phases. These core phases will inform the discussion of the regulatory landscape in Part IV. The NEPA considerations will be addressed as overarching containment considerations in Part V. 


\section{ENHANCING THE REGULATORY LANDSCAPE}

In light of the differences between synthetic biology and rDNA technology, are existing regulatory mechanisms sufficient or is a new regulatory approach necessary? Similar questions have been waged in the context of other FDA-regulated products. For example, opponents of genetically engineered plants produced for human food have urged for decades that the FDA and U.S. Department of Agriculture's (USDA) approach under the Coordinated Framework for the Regulation of Biotechnology ${ }^{111}$ is not enough to protect consumers from the potential harms of genetically engineered plant varieties. ${ }^{12}$ However, the FDA maintains that its approach is adequate and that the process of genetic modification in and of itself does not inherently raise novel safety issues. ${ }^{113}$ Should the same reasoning apply to synthetic biology?

Based on the two core differences between rDNA and synthetic biology discussed in Part II, this article proposes some suggestions across the three core phases in the synthetic biology life-cycle for human and animal drugs. Suggestions will be addressed in relation to the three core phases: (1) human clinical trials and clinical investigations in animals (i.e., the IND or INAD); (2) submission of product application and FDA review of the NDA or NADA; and (3) post-approval and postmarket. Although the FDA has the necessary tools in its drug regulatory toolkit to address many of the novel issues with synthetic biology, there may be administrative hurdles resulting from synthetic biology-specific issues. Containment considerations will also prove complex.

\section{A. Human Clinical Trials and Clinical Investigations in Animals}

The general procedures for new drug and new animal drug approval are relatively similar despite some differences in manufacturing, distribution, and administration. ${ }^{114}$ The IND officially initiates clinical trials for human drugs; as mentioned earlier, most animal clinical trials

111. Coordinated Framework for the Regulation of Biotechnology, 51 Fed. Reg. 23, 302 (June 26, 1986).

112. See Rebecca Bratspies, The Illusion of Care: Regulation, Uncertainty, and Genetically Modified Food Crops, 10 N.Y.U. ENVTL. L.J. 297, 310 (2001).

113. The FDA holds the position that, unless the plant were to fall into the category of a "food additive," it is not generally regarded as safe for use in food; genetically engineered plant products would be regulated as food and subject to existing law and regulations. Similar arguments have been set forth for genetically engineered animals for human food, most prominently the Aquadvantage salmon. The FDA likewise responded with a reiteration of existing law and regulations: the genetically engineered salmon were to be regulated as food also subject to the new animal drug requirements. See FDA BRIEFING PACKET, supra note 38.

114. PETER B. HUTT ET AL., supra note 49 , at 838. 
supporting an NADA can proceed after submission of an application of exemption for investigation. Based on the novelty of the technique and potential concerns regarding inadvertent release and exposure discussed in Part V, the FDA should assess whether this is appropriate for a microbe modified using synthetic biology or whether an INAD should be required to initiate animal clinical testing. The investigational provisions function to provide drug sponsors with the ability to transport the investigational new drug to trial centers and to lay out the test protocol. The information gathered during trials will serve as the basis of the NDA or NADA.

As drug sponsors begin to contemplate research and development in synthetic biology, any guidance from the FDA will be useful. The drug approval process, whether for a new human drug or new animal drug, is both extensive and costly. Advance thinking on the applicability of existing regulatory frameworks, and the types and format of any additional (or different) synthetic biology requirements and considerations, will assist in the structure of clinical trials, methods of data collection, reporting, communications to the FDA, and eventual submission of an NDA or NADA. For example, the FDA recently published draft guidance for industry regarding nanotechnology. ${ }^{115}$ Although extremely general, it provides a number of considerations for industry throughout the research and development process. ${ }^{16}$ A similar document could be developed for synthetic biology; as the interface of nanotechnology and biology (an area termed nanobiotechnology) overlap with synthetic biology, the nanotechnology guidance could alternatively or simultaneously be supplemented to include synthetic biology.

Another broad suggestion is that the FDA examine the application of NEPA to products of synthetic biology. NEPA mandates that all federal agencies assess the environmental impacts of their actions "significantly affect[ing] the quality of the human environment." The approval of a drug application qualifies as a federal action under NEPA. NEPA provides for categorical exclusions (CE) of actions deemed to "not significantly affect the quality of the human environment" that are exempt from preparation of an environmental assessment (EA) and environmental impact statement (EIS). ${ }^{118}$ Through regulation, the FDA

115. FDA, DRAFT GUIDANCE FOR INDUSTRY: CONSIDERING WHETHER AN FDARegulated Product INVOlVES THE APPliCATION OF NANOTEChNOLOGY (2011) [hereinafter NANOTECHNOLOGY GUIDANCE], available at http:/www.fda.gov/Regulatory Information/Guidances/ucm257698.htm; see also Paradise, supra note 39 (discussing the FDA's activities regarding nanotechnology).

116. See NANOTECHNOLOGY GUIDANCE, supra note 115.

117. See 40 C.F.R. $\$ 1508.18$ (2012) (defining “Major Federal action"); 40 C.F.R. $\S 1508.27$ (2012) (defining "significantly").

118. 40 C.F.R. $\S 1508.4$ (2012). 
has created CEs for various product types. ${ }^{119}$ These exclusions are wideranging, with separate regulations applicable to human drugs and biologics; ${ }^{120}$ foods, food additives, and color additives; ${ }^{121}$ animal drugs; ${ }^{122}$ and medical devices. ${ }^{123}$ Most human drugs qualify for a $\mathrm{CE}$ where an NDA, ANDA, or supplement does not increase the use of the active moiety; if it does increase the use of the active moiety, but the estimated concentration of the substance into the aquatic environment is below 1 part per billion; or where the substance occurs naturally in the environment and will not alter significantly the concentration or distribution of the substance, its metabolites, or degradation products in the environment. ${ }^{124}$ Unless one of the CEs apply, or "extraordinary circumstances indicate that the specific proposed action may significantly affect the quality of the human environment" for a particular product-despite technical adherence to a $\mathrm{CE}^{125}$-sponsors must submit an EA. ${ }^{126}$ After reviewing the EA, the FDA must issue either an EIS, detailing the impact on the environment coupled with alternative approaches and mitigation strategies developed with the applicant, or issue a finding of no significant impact (FONSI), negating the need for an EIS. The FDA has issued guidance documents clarifying the EA process for human drugs and biologics applications, ${ }^{127}$ as well as one for genetically engineered animals that contain heritable rDNA constructs. $^{128}$ The rDNA guidance document specifically acknowledges that "at least until we have more experience, most GE animal

119. See generally 21 C.F.R. $\$ 25$ (2012).

120. See 21 C.F.R. $\$ 25.31(2012)$.

121. See 21 C.F.R. $\$ 25.32(2012)$.

122. See 21 C.F.R. $\$ 25.33(2012)$.

123. See 21 C.F.R. $\$ 25.34(2012)$

124. See 21 C.F.R. $\$ 25.31$ (a)-(c) (2012). There are additional categories of exclusion provided for human drugs and biologics. The core exclusions for animal drugs are similar. See 21 C.F.R. § 25.33 (2012).

125. 21 C.F.R. $\$ 25.21$ (2012).

126. The FDA provides guidance for applying these regulations to both new drugs and new animal drugs. See FDA, GUIDANCE FOR INDUSTRY: ENVIRONMENTAL ASSESSMENT OF HUMAN DRUG AND BIOLOGICS APPLICATIONS (1998) [hereinafter BIOLOGICS APPLICATIONS GUIDANCE], available at http://www.fda.gov/downloads/Drugs/ GuidanceComplianceRegulatoryInformation/Guidances/ucm070561.pdf; see also FDA, GUIDANCE FOR INDUSTRY: ENVIRONMENTAL IMPACT ASSESSMENTS (EIA'S) FOR Veterinary Medicinal Products (VMP's)-Phase I, Final Guidance (2011), available at http://www.fda.gov/downloads/AnimalVeterinary/GuidanceCompliance Enforcement/GuidanceforIndustry/ucm052424.pdf; FDA, GUIDANCE FOR INDUSTRY: FDA Approval of New ANIMAL Drugs for MinOR USES AND FOR MINOR SPECIES (2008), available at http://www.fda.gov/downloads/AnimalVeterinary/GuidanceCompliance Enforcement/GuidanceforIndustry/ucm052375.pdf.

127. Biologics ApPliCATIONS GuidanCE, supra note 126.

128. See FDA, FINAL GUIDANCE FOR INDUSTRY 187: REGULATION OF GENETICALly EngINEEREd ANImals ContaInING Heritable ReCombinant DNA Constructs (2009). 
applications would have to be evaluated to determine whether such an application individually or cumulatively affects the environment (i.e., whether an extraordinary circumstance exists). ${ }^{, 129}$ The FDA should clarify if synthetic biology products are excluded or subject to an EA (or full EIS) at the IND and NDA or NADA stage. This clarification entails categorization of the types of synthetic biology processes contemplated for use in human and animal drugs both currently and in the near future.

Other federal agencies have begun to address similar issues regarding the scope of existing regulations as applied to synthetic biology. Notably, the Office of the General Counsel for the U.S. Department of Energy recently published a Final Rule in the Federal Register, effective November 14, 2011, which revises its NEPA implementing procedures. ${ }^{130}$ The revisions focus on the categorical exclusions to NEPA and add a new "integral element" applicable to the categorical exclusions in its Appendix $B .{ }^{131}$ The new language reads:

The classes of actions listed below include the following conditions as integral elements of the classes of actions. To fit within the classes of actions listed below, a proposal must be one that would not: ... (5) Involve genetically engineered organisms, synthetic biology, governmentally designated noxious weeds, or invasive species, unless the proposed activity would be contained or confined in a manner designed and operated to prevent unauthorized release into the environment and conducted in accordance with applicable requirements, such as those of the Department of Agriculture, the Environmental Protection Agency, and the National Institutes of Health. ${ }^{132}$

In addition to reassessing its NEPA exclusions, the FDA should also integrate appropriate safeguards into its Good Laboratory Practices, Good Clinical Practices, and Good Manufacturing Practices that span research, development, and market entry of synthetic biology products ${ }^{133}$ and various guidance documents relating to those topics. Any additional requirements for synthetic biology would necessarily tie into the NEPA

129. Id. at 25 .

130. National Environmental Policy Act Implementing Procedures, 75 Fed. Reg. 63,764 (Oct. 13, 2011).

131. Id.

132. Id. at $63,789-90$. The rule further provides: "In order to qualify for a categorical exclusion, a proposed action would have to prevent unauthorized releases into the environment, comply with all applicable requirements, and meet other conditions of the applicable categorical exclusion." Id. The NIH Guidelines for Research Involving Recombinant DNA Molecules is specifically offered as an example of applicable guidelines. $I d$.

133. These safeguards include the following regulations: 21 C.F.R. $\S \S 26,58,210-11$ (2012). 
considerations as well in terms of production, containment, monitoring, and recordkeeping.

For new human drugs, the FDA should also assess whether the informed consent mechanisms built into the regulations adequately protect human subjects in clinical trials. ${ }^{134}$ Should human subjects be informed of novel issues prior to enrolling in a trial? Are there additional measures to report as clinical data? Should longitudinal aspects be built into the clinical trial protocol to capture whether the synthetic biology product has unintended long-term consequences on the body? Recent bioethics literature advises that these issues should not be taken lightly and that the informed consent process may need to be tailored to the technology involved. ${ }^{135}$

\section{B. NDA or NADA Review by FDA}

The NDA or NADA is the application to the FDA consisting of the cumulative data and other requisite information gleaned from the human or animal clinical trials. In addition to the data supporting safety and efficacy, the application will also include labeling aspects, manufacturing assurances, and various other elements. ${ }^{136}$ The FDA should contemplate how to link adherence to any relevant guidelines-including the NIH Guidelines $^{137}$ and Recombinant DNA Advisory Committee assessments ${ }^{138}$-to the information provided in the application.

The FDA should also consider whether any synthetic biologyspecific information should be required at this stage. Similar to the internal policy developed for nanotechnology drugs, ${ }^{139}$ the FDA's Center for Drug Evaluation and Research could implement a manual of policy and procedures (MaPP) to gather and track specific information regarding synthetic biology products. The nanotechnology MaPP, published in May 2010, instructs drug reviewers to capture "relevant information about nanomaterial-containing drugs" that will be entered into a nanotechnology database and tracked post-market. ${ }^{140}$ However,

134. See 21 C.F.R. $\S \S 50,56$ (2012).

135. See, e.g., David B. Resnik \& Sally S. Tinkle, Ethical Issues in Clinical Trials Involving Nanomedicine, 28 CONTEMP. CLINICAL TRIALS 433 (2007), available at http:/www.ncbi.nlm.nih.gov/pmc/articles/PMC2695593/.

136. See 21 U.S.C. $\S 355$ (b) (2006 \& Supp. 2011).

137. NAT'L INSTS. OF HEALTH, supra note 101.

138. See About Recombinant Advisory Committee (RAC), NAT'L INSTS. OF HEALTH, http://oba.od.nih.gov/rdna_rac/rac_about.html (last visited Aug. 9, 2012).

139. See Office of Pharm. SCI., Ctr. For Drug Evaluation \& Research, FDA, MAPP 5015.9, REPORTING FORMAT FOR NANOTECHNOLOGY-RELATED INFORMATION IN CMC REVIEW (2010), available at http://www.fda.gov/downloads/AboutFDA/ CentersOffices/CDER/ManualofPoliciesProcedures/UCM214304.pdf.

140. Id. at 2 . 
one weakness in the existing nanotechnology MaPP is that drug reviewers bear the initial data collection burden rather than the industry; the FDA should consider putting the burden on industry to generate this information for the NDA or NADA.

As for labeling of both human drug and animal drug products, the FDA will need to determine whether the labeling should reflect the synthetic biology aspects of the product, including warnings to prescribing physicians and veterinarians or consumers. This harkens back to advocacy for mandatory labeling of genetically engineered foods. However, in the context of new human drugs and animal drugs, the role of adequate warnings and adequate directions for use as required by the FDCA and implementing regulations may dictate more urgency in mandatory labeling of particular aspects of the products. In order to answer these and other questions, the FDA should create a synthetic biology advisory committee to assist with review and categorization of synthetic biology products. Given the current state of synthetic biology drug research, the FDA might have limited time to evaluate these questions proactively as the science develops. This labeling issue dovetails into the discussion of the utilization of REMS.

The FDA can obligate the sponsor to provide a REMS as a requirement for approval of a new human drug. ${ }^{141}$ Amendments to the FDCA provide the FDA with expanded authority to require additional safeguards for particular products upon review. The FDA has already implemented REMS for several new NDAs and prior-approved NDAs. ${ }^{142}$ These REMS can be drug-class specific, or applicable to an individual NDA. For example, the FDA has developed universal REMS for all opioid drug products. ${ }^{143}$ In addition to the forms of REMS described above, a synthetic biology REMS could integrate assessments of environmental impact of exposure and disposal under their authority to assure safe use, even if NEPA does not require an EA. For example, a REMS might require some type of self-destruct mechanism to be incorporated into synthetic biology drug products, which could take the form of a "kill switch" that activates when excreted or expelled from the human body. ${ }^{144}$ However, REMS provisions contained within the recently enacted legislation do not apply to animal drugs and NADAs; mechanisms are more limited for the FDA in that context, largely

141. See 21 U.S.C. $\S \S 355-1,355$ (p) (2006 \& Supp. 2011).

142. See Approved REMS, supra note 71.

143. See List of Extended-Release and Long-Acting Opioid Products Required to Have an Opioid REMS, FDA, http://www.fda.gov/Drugs/DrugSafety/Informationby DrugClass/ucm251735.htm (last visited Aug. 9, 2012).

144. See infra Part V. 
consisting of adverse event reporting and required information about labeling or manufacturing changes.

\section{Post-Approval and Post-Market}

The FDA maintains traditional post-approval authority for withdrawal of an approved NDA or NADA. ${ }^{145}$ When evidence or data accumulates suggesting safety or efficacy issues with an approved synthetic biology product, the FDA can act to remove the product approval using this existing authority subject to the notice and opportunity for hearing requirements. ${ }^{146}$ Regular reporting requirements for the manufacturer, as well as targeted adverse reports by manufacturers, consumers, and physicians and veterinarians, will also serve to flag problems arising with synthetic biology products.

When the FDA identifies a potential problem with regard to a human drug product either at the application phase or earlier, the 2007 amendments to the FDCA grant the FDA the authority to require a REMS at the time of the initial NDA review or as a requirement added to an already-approved NDA. ${ }^{147}$ In addition to requiring a REMS, the recently enacted legislation provides the FDA with the power to require additional clinical trials and other follow-up studies, as well as the obligation for manufacturers to integrate "new safety information" that arises into the label. ${ }^{148}$ These provisions bolster the FDA's post-market power, expanding what used to be termed "Phase IV" requirements. ${ }^{149}$ All of these provisions will be critical to the FDA with regard to new drugs developed using synthetic biology. As discussed above, these new provisions do not account for environmental safety or containment concerns, nor do they apply to NADAs. Part V specifically highlights the unique containment concerns raised by synthetic biology.

\section{OVERARCHING CONTAINMENT CONSIDERATIONS}

Questions about containment of synthetic biology products are perhaps the most pressing for regulatory purposes. It is currently unknown how synthetic organisms will interact with the environment or what effect, if any, they will have on humans or animals who are either purposefully or inadvertently exposed. The FDA should expend the most time and resources supporting external research and developing policy in this area. Due to the life-cycle trajectory of these products,

145. 21 U.S.C. $\S \S 355(\mathrm{e}), 360 \mathrm{~b}$ (e) (2006 \& Supp. 2011).

146. 21 U.S.C. $\S \S 355(\mathrm{e}), 360 \mathrm{~b}(\mathrm{e})(2006$ \& Supp. 2011).

147. 21 U.S.C. $\$ 355-1$ (2006 \& Supp. 2011).

148. 21 U.S.C. $\$ 355(0)$ (2006 \& Supp. 2011).

149. Id. 
containment considerations will be a collaborative effort on behalf of the FDA and various other federal agencies, including the Environmental Protection Agency and the USDA. As discussed in Parts III and IV, new human drugs and animal drugs are largely exempt from NEPA requirements. The question going forward is whether this exemption should hold true for products utilizing synthetic biology. At minimum, the authors urge that spread-prevention mechanisms be required as a research, development, and manufacturing aspect of synthetic biology.

To assess the range of overarching containment considerations applicable to synthetic biology products envisioned for medical use, the authors use the example of development of an engineered E.coli capable of interrupting the normal inter-cellular signaling of the Cholera pathogen V.cholerae to prevent secretion of the Cholera toxin in the gut. ${ }^{150}$ This example is a near-term potential application of synthetic biology. The resulting synthetic organism would be used to treat cholera by introduction into an affected human or animal where it would live alongside the naturally occurring gut bacteria until excreted from the body.

Figure 3 illustrates the chain of environmental release and exposure throughout the production, testing, and eventual introduction of the synthetic biology E.coli product. The solid black lines in Figure 3 illustrate intentional actions of the synthetic biology drug sponsor in the production, development, disposal, and marketing of the product; the dotted black lines illustrate the unintentional, yet causal, result of the sponsor activity on environmental release and exposure. For this example, the synthetic organism would be released into the environment in various ways from the beginning of any human or animal trials. That is the case unless great lengths are taken to completely isolate the humans or animals involved. Thus, disposal issues would arise early on in the IND and NDA process and continue throughout the life of the developing product.

150. This example is modeled on Ruder et al., supra note 24 . 
Figure 3. Containment Considerations *

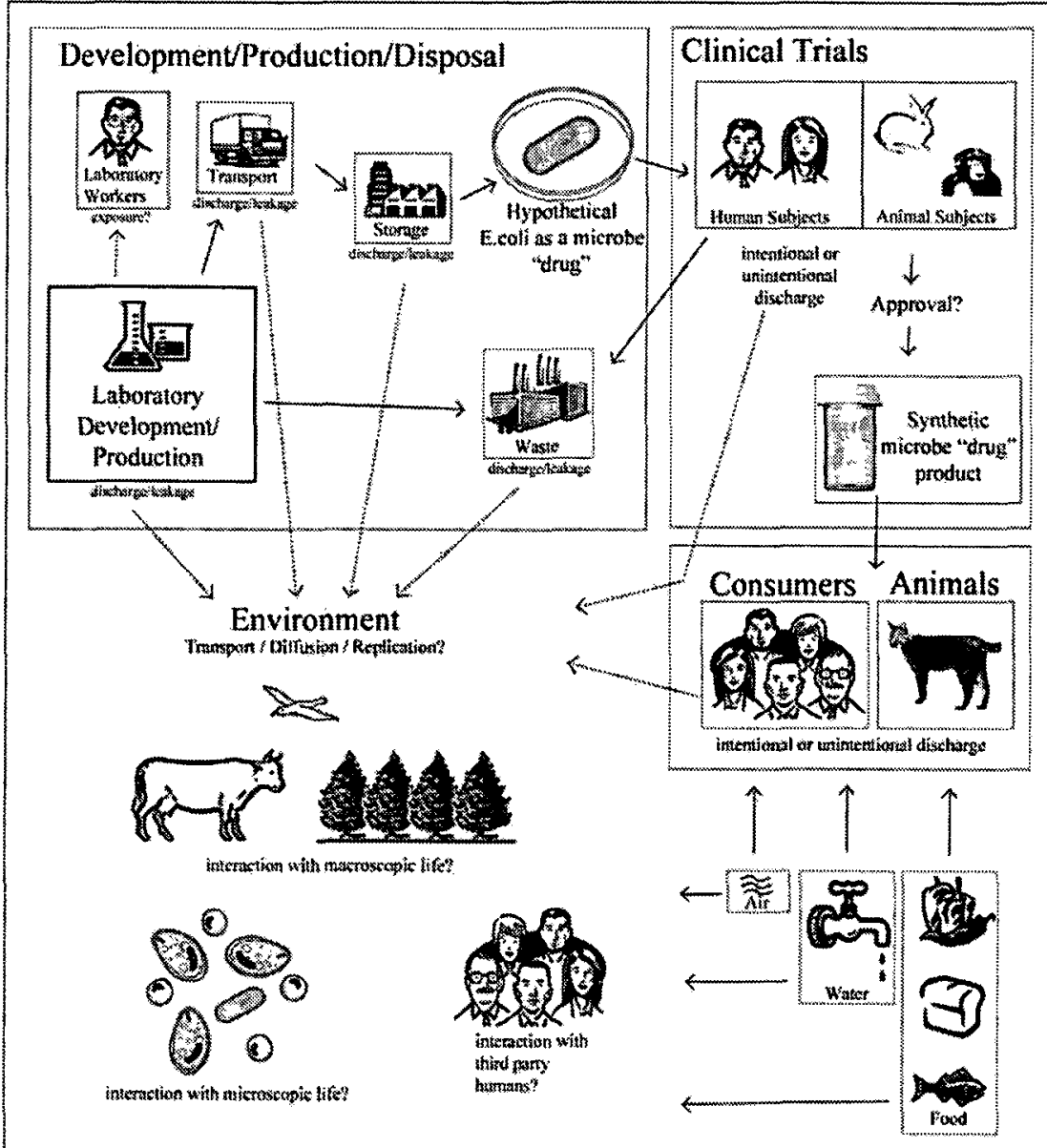

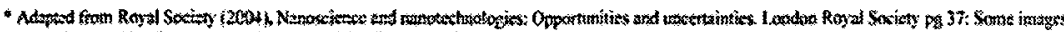

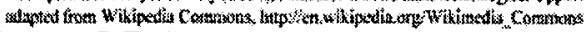

Without research, it is difficult to predict what impact the multiple routes of exposure and release of the synthetic E.coli would have on exposed humans and the environment. To ameliorate potential harms, various mechanisms have been proposed to prevent the spread of synthetic organisms outside the laboratory. These proposed mechanisms include modification of the genetic material of the synthetic organisms to reduce its ability to survive in the natural environment. These mechanisms could be required during the earliest stages of synthetic organism development, long before the synthetic organism is introduced 
to humans or animals as clinical treatment. ${ }^{151}$ Figure 3 illustrates this phase in the life cycle chain of the product with a bold box labeled "Laboratory Development/Production," However, the clinical efficacy of a synthetic organism depends on some level of robustness, which may exacerbate environmental concerns. This tension between robustness and efficacy cannot be accurately assessed without experimentation. It may be possible to design control mechanisms in such a way that they do not significantly impact the intended therapy's efficacy. As a practical matter, these mechanisms would require the creation of a completely new microbe, and it is unclear whether the FDA has or would ever require broad limitations to the platform used for a technology from the outset. As discussed earlier, the FDA generally regulates products rather than processes.

The spread-prevention mechanisms that could be built into this phase to address containment concerns can be broadly classified into three groups: (1) engineered organisms that have reduced viability in the natural environment; (2) engineered organisms that self-destruct; and (3) engineered organisms that cannot transfer genetic material to or from natural organisms. Each of these mechanisms could be used in isolation or combination with one another and would address potential harm to the environment, third-party humans, and animals that are unintentionally exposed. ${ }^{152}$ Similar mechanisms have been examined for genetically engineered organisms. ${ }^{153}$

\section{A. Reduced-Viability Mechanisms}

Reduced-viability mechanisms would be applicable to minimize the environmental impact of the hypothetical engineered E.coli from Figure 3. This mechanism would involve engineering the synthetic E.coli so that it is dependent upon an exogenous supply of a nutrient that does not occur in food chains or natural habitats. ${ }^{154}$ The population of the engineered organism introduced into the gut of a person would be limited by the amount of nutrient supplied. Upon release of the synthetic organism into the environment through any of the intentional or

151. This proposal implicates the "process" phase of the new drug approval, rather than the "product."

152. The authors propose these broad classifications based on the combination of the following sources: Philippe Marliere, The Farther the Safer: A Manifesto for Securely Navigating Synthetic Species Away from the Old Living World, 3 SYST. SYNTH. BIOL. 77 (2009); George Church, Let Us Go Forth and Safely Multiply, 438 NATURE 423, 423 (2005); Philip Ball, Starting From Scratch, 431 NATURE 624, 626 (2004).

153. Comm. ON BIological CONFINEMENT OF Genetically ENGINEered Organisms, Nat'l Research Council, Biological Confinement of Genetically ENGINEERED ORGANISMS (2004).

154. Marliere, supra note 152 , at 80. 
unintentional routes seen in Figure 3, the engineered E.coli would be deprived of the required nutrient and would eventually die.

Notably, engineering a bacterium that uses a reduced viability control mechanism would require re-wiring several biological pathways in the cell. At present, scientists may not have the ability to create such a synthetic organism, so this approach is forward-looking. Moreover, with the amount of re-wiring that would be required, it is not practical to use standard recombinant DNA techniques. Thus, this method of containment may only be available for synthetic biology.

\section{B. Self-Destruct Mechanisms}

Another way to minimize the environmental impact of the hypothetical engineered E.coli is to control its population by incorporating self-destruct mechanisms into the organism's genome. ${ }^{155}$ Based on scientists' current understanding of bacterial population control genes, it may be possible to create an engineered microbe drug that incorporates a self-destruct mechanism using standard recombinant DNA techniques. For example, the synthetic E.coli's innate population sensing genes could be re-wired to result in cell death after reaching a certain population density. Alternatively, a gene circuit could be employed that triggers a self-destruct mechanism after a pre-determined number of cell divisions. These mechanisms would not necessarily prevent the spread of the synthetic organisms in the environment, but would place a ceiling on the potential population. However, this technique would also limit the population density of the synthetic organism in the gut, thus potentially reducing its clinical effects.

\section{Preventing Genetic Transfer}

The transference of genetic material among and between cells is a common phenomenon, especially among bacteria. As seen in Figure 3, our hypothetical E.coli microbe drug would have the opportunity to interact with naturally occurring microbes in the environment. This opportunity for interaction between microbes could result in a hazardous trait being conferred to a naturally occurring organism or the synthetic E.coli circumventing the engineered control mechanisms intended to contain its spread. In either case, steps can be taken to prevent gene transfer. One possible method consists of re-writing the gene codons, which are naturally used for translating mRNA to protein. ${ }^{156}$ This method would involve a completely re-written genome and changes to

155. Ball, supra note 152.

156. Marliere, supra note 152 , at 82. 
some native biomolecules, such as tRNAs, and their associated proteins. ${ }^{157}$ The re-written gene codons of the synthetic organism would be incompatible with those of naturally occurring organisms and, therefore, any genetic transfers that take place would not likely confer any useful sequence.

Safety mechanisms preventing genetic transfers are forward-looking because they would require completely re-writing a genome and engineering several biomolecules. Thus, it is not possible to use this method with current recombinant DNA techniques. This method delves purely in the realm of synthetic biology.

Alternatively, a simpler approach to prevent gene transfer might involve removing genetic sequences known to move around easily. Scientists have identified several of these "transposable elements" 158 and could easily remove them using standard recombinant DNA techniques. However, scientists might not know of all the transposable elements; thus, gene transfer would still occur between the synthetic organism and natural organisms. Furthermore, the transposable elements of native microorganisms would remain present and transferable to the synthetic microbe. Thus, this strategy is likely possible using rDNA methods, but it is far from ideal.

\section{CONCLUSION}

Synthetic biology is inevitably making its way into medical care and medical products. Using a life cycle approach, this article examined the statutory and regulatory framework for human drugs, animal drugs, and cosmetics, and assessed the application of that framework to emerging synthetic biology developments. This article identified potential gaps in regulation and suggested mechanisms for the FDA to address these gaps in its regulatory paradigm to assure that future new drug and new animal drug products developed using synthetic biology are appropriately assessed and ushered into the market. The suggestions track the spectrum of animal clinical investigations and human clinical trials, submission of product application and FDA review, post-approval and post-market, and overarching containment considerations.

This article concludes that the FDA regulatory framework is capable of capturing the research and development, clinical trial, review and approval, and post-market approval periods for synthetic biologybased new human and animal drugs. However, self-regulation in the realm of cosmetics is troublesome because the FDA struggles to enforce the fine line between drugs and cosmetics. Perhaps most critical for the

157. Id.

158. Church, supra note 152. 
regulatory landscape for synthetic biology products is that environmental and containment safeguards, as with most FDA regulated products, are almost nonexistent. Given the nature and characteristics of synthetic biology, the establishment of adequate containment safeguards needs to be considered. The discretion and authority to act is largely present in general NEPA provisions, though the FDA must exercise that authority via rulemaking and implementation of clear and consistent policies. 